\title{
Investigating the effects of different factors on development of open source enterprise resources planning software packages
}

\author{
Mehdi Ghorbaninia*
}

Department of Information Technology, College of Engineering, Buin Zahra Branch, Islamic Azad University, Buin Zahra, Iran

CH R O I C E A B S T RACT

Article history:

Received January 28, 2014

Accepted 20 June 2014

Available online

June 252014

Keywords:

Open source software package

Enterprise resource planning

Fundamental factors

\begin{abstract}
This paper investigates the effects of different factors on development of open source enterprise resources planning software packages. The study designs a questionnaire in Likert scale and distributes it among 210 experts in the field of open source software package development. Cronbach alpha has been calculated as 0.93 , which is well above the minimum acceptable level. Using Pearson correlation as well as stepwise regression analysis, the study determines three most important factors including fundamental issues, during and after implementation of open source software development. The study also determines a positive and strong relationship between fundamental factors and after implementation factors $(r=0.9006$, Sig. $=0.000)$.
\end{abstract}

\section{Introduction}

During the past few years, there have been increasing interests in development open source software packages. Android has become famous for providing open source architecture in mobile devices and people feel more confident to use open access software packages (Madey et al., 2002; Buehler, 2013; Hertel et al., 2013; Crowston \& Scozzi, 2002; Xu \& Jones, 2010). Peng et al. (2013) adopted a finegrained view of network relations to study the effect of network ties on the success of open access system development. Through investigating the development of open access development projects, they reported that co-membership among project teams was an important mechanism for constructing network ties. Nevertheless, network ties among projects not only confer advantage, but also incur different expenses and due to the various growth patterns of expense and advantage, network ties could have a diminishing return to project success. Besides, they reported network ties of leaderfollower kind and follower-leader kind were more beneficial to open source system success than other kinds of ties, and network ties connecting to projects of later development stages were more beneficial than those connecting to projects of earlier stages were.

*Corresponding author.

E-mail addresses: ghorbaninia@gmail.com (M. Ghorbaninia) 
According to Buehler (2013), the concept, design, and development of institutional repository (IR) software was conceived and built by many academics, libraries, and software developers to make necessary change in the scholarly communication process of making journal papers globally available. Many research tools have made open access paper searching a less daunting proposition by utilizing the OAI-PMH metadata harvesting technology. Subramaniam et al. (2009) studied open source software (OSS) success using longitudinal data on OSS projects. They reported that restrictive OSS licenses had an adverse effect on OSS success. On further analysis, restrictive OSS license was detected to be negatively associated with developer interest, but was positively related to the interest of non-developer users and project administrators. They also explained that developer and nondeveloper interest in the OSS project and the project activity levels in any time substantially influence the project success measures in subsequent period.

\section{The proposed study}

This paper investigates the effects of different factors on development of open source enterprise resources planning software packages. Fig. 1 shows the proposed study of this paper.

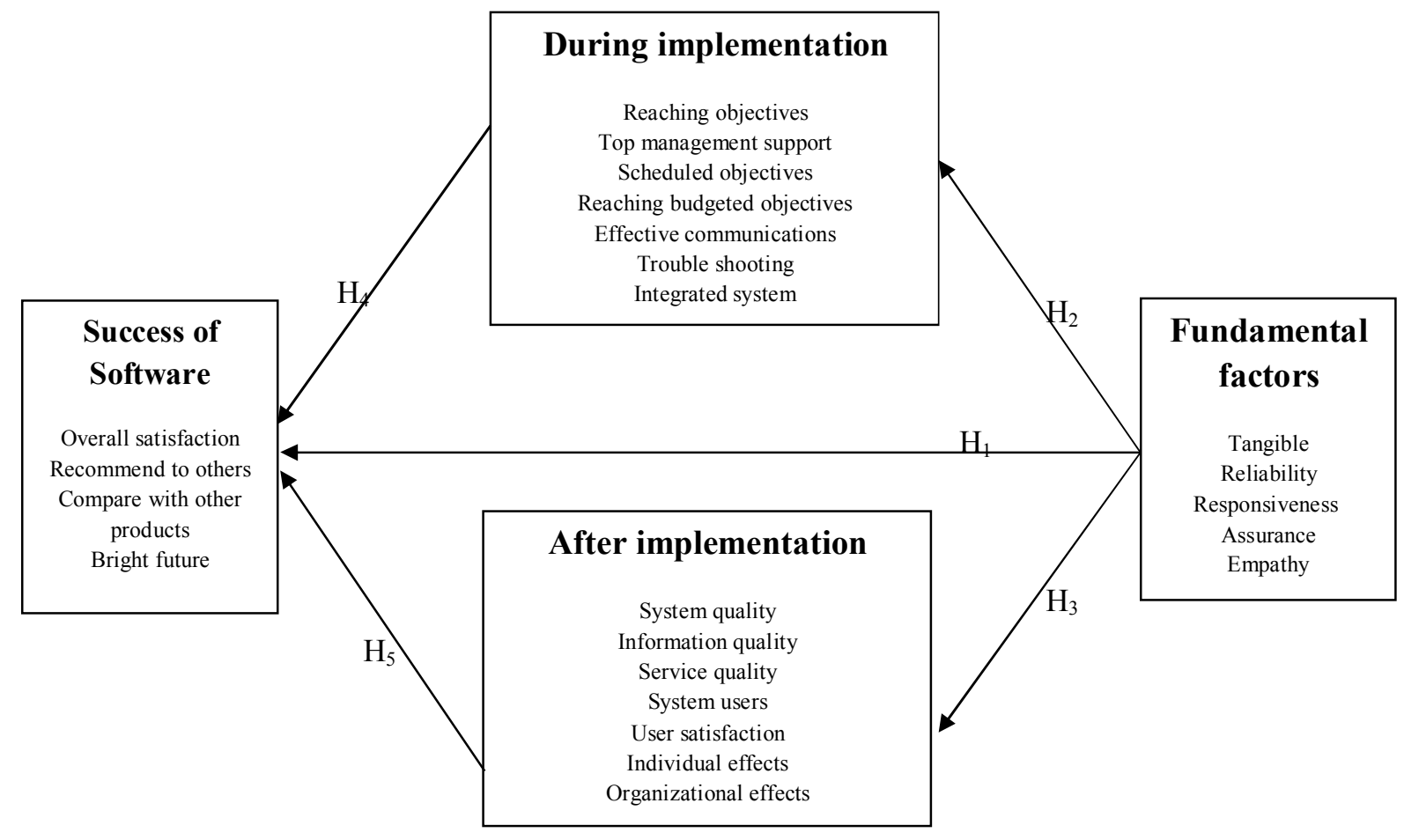

Fig. 1. The proposed study

As we can observe from the results of Fig. 1, there are five hypotheses associated with the proposed study of this paper as follows,

1. Fundamental factors influence on success of software.

2. Fundamental factors influence on during the implementation issues.

3. Fundamental factors influence on after the implementation issues.

4. During implementation factors influence on success of software.

5. After implementation factors influence on success of software. 
In order to examine the hypotheses of this survey, a questionnaire has been designed and it has been distributed among some experts in software development in city of Tehran, Iran. Cronbach alpha has been calculated as 0.93 , which is well above the minimum desirable level. The sample size is calculated as follows,

$n=\frac{N \times z_{\alpha / 2}^{2} \times p \times q}{\varepsilon^{2} \times(N-1)+z_{\alpha / 2}^{2} \times p \times q}$,

where $N$ is the population size, $p=1-q$ represents the yes/no categories, $z_{\alpha / 2}$ is CDF of normal distribution and finally $\varepsilon$ is the error term. Since we have $p=0.5, z_{\alpha / 2}=1.96$ and $N=460$, the number of sample size is calculated as $n=210$. We have applied Kolmogorov-Smirnov test and the results have indicated that the data were normally distributed. Therefore, we use parametric test to verify the hypotheses of the survey.

\section{The results}

In this section, we present details of our findings on testing different hypotheses of the survey.

\subsection{The first hypothesis: The effect of fundamental factors on the success of software}

The first hypothesis of the survey investigates the effects of fundamental factors on the success of software implementation. Table 1 shows the results of our survey.

Table 1

The summary of implementation of Pearson correlation ratio

\begin{tabular}{cccc}
\hline & & Fundamental & Success \\
\hline \multirow{2}{*}{ Fundamental } & Pearson Correlation & 1 & $.512^{* * *}$ \\
& Sig. (2-tailed) & 210 & .000 \\
& $\mathrm{~N}$ & $.512^{* *}$ & 210 \\
\multirow{2}{*}{ Success } & Pearson Correlation & .000 & 1 \\
& Sig. (2-tailed) & 210 & 210 \\
\hline **. Correlation is significant at the 0.01 level (2-tailed). & $\mathrm{N}$ & &
\end{tabular}

As we can observe from the results of Table 1, there is a meaningful relationship between fundamental factors and success in development of an open access software package in enterprise resources planning management. Therefore, the first hypothesis is confirmed.

\subsection{The second hypothesis: The effect of fundamental factors on development issues}

The second hypothesis of the survey studies the effects of fundamental factors on development phase factors. Table 2 demonstrates the results of our survey.

Table 2

The summary of implementation of Pearson correlation ratio for the second hypothesis

\begin{tabular}{cccc}
\hline & & Fundamental & Success \\
\hline \multirow{2}{*}{ Fundamental } & Pearson Correlation & 1 & $.765^{* *}$ \\
& Sig. (2-tailed) & 210 & .000 \\
\hline \multirow{2}{*}{ Development issues } & $\mathrm{N}$ & $.765^{* *}$ & 210 \\
& Pearson Correlation & .000 & 1 \\
& Sig. (2-tailed) & 210 & 210 \\
\hline
\end{tabular}

**. Correlation is significant at the 0.01 level (2-tailed). 
As we can observe from the results of Table 2, there is a meaningful relationship between fundamental factors and issues associated with open access software development in enterprise resources planning, which confirms the second hypothesis of the survey.

\subsection{The third hypothesis: The effect of fundamental factors on after installation development}

The third hypothesis of the survey studies the impacts of fundamental factors on the success of software implementation after it is supplied to consumer. Table 3 presents the results of our survey.

Table 3

The summary of implementation of Pearson correlation ratio for testing the third hypothesis

\begin{tabular}{cccc}
\hline & & Fundamental & Success \\
\hline \multirow{3}{*}{ Fundamental } & Pearson Correlation & 1 & $.906^{* *}$ \\
& Sig. (2-tailed) & 210 & .000 \\
& $\mathrm{~N}$ & $.906^{* *}$ & 210 \\
\hline \multirow{3}{*}{ After implementation } & Pearson Correlation & .000 & 1 \\
& Sig. (2-tailed) & 210 & 210 \\
\hline **. Correlation is significant at the 0.01 level (2-tailed). & $\mathrm{N}$ & &
\end{tabular}

As we can see from the results of Table 3, there is a strong and meaningful relationship between fundamental factors and after package is supplied to consumer, which confirms the third hypothesis.

\subsection{The fourth hypothesis: The effect of during the implementation on the success of software}

The fourth hypothesis of the survey studies the effects of the factors in implementation stage on the success of software implementation. Table 4 presents the results of our survey.

Table 4

The summary of implementation of Pearson correlation ratio

\begin{tabular}{cccc}
\hline & & Fundamental & Success \\
\hline \multirow{2}{*}{ Fundamental } & Pearson Correlation & 1 & $.765^{* *}$ \\
& Sig. (2-tailed) & 210 & .000 \\
& $\mathrm{~N}$ & $.765^{* *}$ & 210 \\
\hline \multirow{3}{*}{ During the implementation } & Pearson Correlation & .000 & 1 \\
& Sig. (2-tailed) & 210 & 210 \\
\hline **. & $\mathrm{N}$ & &
\end{tabular}

**. Correlation is significant at the 0.01 level (2-tailed).

As we can observe from the results of Table 4, there is a meaningful relationship between fundamental factors and factors during the implementation in development of an open access software package in enterprise resources planning. Therefore, the fourth hypothesis is confirmed.

\subsection{The fifth hypothesis: The effect of after implementation factors on after installation development}

The last hypothesis of the survey studies the impacts of after implementation factors on the success of software development. Table 5 presents the results of our survey.

Table 5

The summary of implementation of Pearson correlation ratio for testing the last hypothesis

\begin{tabular}{cccc}
\hline & & Fundamental & Success \\
\hline \multirow{2}{*}{ Fundamental } & Pearson Correlation & 1 & $.659^{* * *}$ \\
& Sig. (2-tailed) & 210 & .000 \\
& $\mathrm{~N}$ & $.659^{* *}$ & 210 \\
\hline \multirow{2}{*}{ After implementation } & Pearson Correlation & .000 & 1 \\
& Sig. (2-tailed) & 210 & 210 \\
\hline
\end{tabular}

**. Correlation is significant at the 0.01 level (2-tailed). 
As we can see from the results of Table 5, there is a strong and meaningful relationship between after implementation factors and success of product development. Therefore, the last hypothesis is confirmed.

\section{Conclusion}

During the past few years, there have been increasing interests in development open source software packages. These software packages help user learn more about the features of the software and make necessary changes to customize the package. In this paper, we have presented an empirical investigation to find the effects of different factors on the success of open access software package development. The study has detected a positive and meaningful relationship between various factors on software development either during or after implementation. In other words, although fundamental factors influence on the success of product development, it also influences on the success of product development indirectly. The results of this study are in agreement with other findings such as Gwebu and Wang (2011).

The results of our study are also consistent with findings reported by Sen et al. (2008). In their survey, they studied how the motivations and behaviors of OSS developers influenced their preference among the three common OSS license types namely, Strong-Copyleft, Weak-Copyleft, and Non-Copyleft. In spite of the importance of the license type and developers to OSS projects, there was little insight in open source literature of the license choice from a developer's perspective. They reported that the intrinsic motivation of challenge (problem solving) was associated with the developers' preference for licenses with moderate restrictions, while the extrinsic motivation of status was associated with developers' preference for licenses with least restrictions. They also detected that when selecting an OSS license, a developer's attitude toward the software redistribution rights conflicts with his/her behavior toward preserving the social benefits of open source. A major implication of their findings was that OSS managers who want to absorb a limited number of highly skilled programmers to their open source project ought to choose a restrictive OSS license. Similarly, managers of software projects for social programs could absorb more developers by selecting a restrictive OSS license.

\section{Acknowledgement}

The authors would like to thank the anonymous referees for constructive comments on earlier version of this paper.

\section{References}

Buehler, M.A. (2013). Academic shift towards open access. Demystifying the Institutional Repository for Success, 29-62.

Crowston, K., \& Scozzi, B. (2002). Open source software projects as virtual organisations: competency rallying for software development. IEE Proceedings-Software, 149(1), 3-17.

Gwebu, K. L., \& Wang, J. (2011). Adoption of Open Source Software: The role of social identification. Decision Support Systems, 51(1), 220-229.

Hertel, G., Niedner, S., \& Herrmann, S. (2003). Motivation of software developers in Open Source projects: an Internet-based survey of contributors to the Linux kernel. Research policy, 32(7), 1159-1177.

Madey, G., Freeh, V., \& Tynan, R. (2002). The open source software development phenomenon: An analysis based on social network theory. AMCIS 2002 Proceedings, 247.

Peng, G., Wan, Y., \& Woodlock, P. (2013). Network ties and the success of open source software development. The Journal of Strategic Information Systems, 22(4), 269-281.

Sen, R., Subramaniam, C., \& Nelson, M. L. (2008). Determinants of the choice of open source software license. Journal of Management Information Systems,25(3), 207-240. 
1876

Subramaniam, C., Sen, R., \& Nelson, M. L. (2009). Determinants of open source software project success: A longitudinal study. Decision Support Systems, 46(2), 576-585.

$\mathrm{Xu}, \mathrm{B} .$, \& Jones, D. R. (2010). Volunteers' participation in open source software development: a study from the social-relational perspective. ACM SIGMIS Database, 41(3), 69-84. 